\title{
Evaluation of a modified GnRH-based timed-AI protocol associated with estrus detection in beef heifers inseminated with sex-selected or conventional semen ${ }^{\text {is }}$
}

\author{
M.G. Colazo a, *, P. Whittaker ${ }^{\text {b }}$, K. Macmillan ${ }^{\text {a }}$, D. Bignell ${ }^{\text {a }}$, G. Boender ${ }^{\text {b }}$, \\ R. de Carvalho Guimaraes ${ }^{\mathrm{C}}$, R.J. Mapletoft ${ }^{\mathrm{d}}$ \\ ${ }^{a}$ Livestock Research Section, Alberta Agriculture and Forestry, Edmonton, T6H 5T6, Canada \\ ${ }^{\mathrm{b}}$ The Farm Animal Hospital, Leduc, T9E 6Z9, Canada \\ c Sao Paulo State University, Aracatuba, 16050-680, Brazil \\ ${ }^{\mathrm{d}}$ Western College of Veterinary Medicine, University of Saskatchewan, Saskatoon, S7N 5B4, Canada
}

\section{A R T I C L E I N F O}

\section{Article history:}

Received 15 December 2017

Received in revised form

24 May 2018

Accepted 29 May 2018

Available online 31 May 2018

\section{Keywords:}

Estrus response

Pregnancy per AI

Cyclicity status

Estrus detection patches

\begin{abstract}
A B S T R A C T
The main objective was to compare pregnancy per $\mathrm{AI}(\mathrm{P} / \mathrm{AI})$ between sex-selected and conventional semen in cyclic beef heifers subjected to a 5-day Co-synch plus CIDR protocol and evaluated the usefulness of an estrus detection (ED) aid to identify heifers that were most likely to conceive. This study also determined if the expression of estrus before timed-AI (TAI) would be associated with increased P/AI in acyclic heifers inseminated with conventional semen. Heifers $(n=1690 ; 320-523 \mathrm{~kg}$ of body weight, and $13-15$ mo of age) at three locations over 2 years were scanned by ultrasonography to determine cyclicity (presence of luteal tissue) and reproductive tract normalcy. Cyclic heifers $(n=1331)$ received a progesterone releasing device (CIDR) on Day 0, CIDR removal and $500 \mu \mathrm{g}$ of cloprostenol (PGF) on Day 5, and $100 \mu \mathrm{g}$ of $\mathrm{GnRH}$ along with TAI on Day 8. Acyclic heifers $(\mathrm{n}=275)$ received the same treatment with the addition of GnRH on Day 0. On Day 5, all heifers received ED patches (Estrotect ${ }^{\mathrm{TM}}$ ) that were scored from 0 to 3, based on color change between initial application and Day 8; $0=$ unchanged, $1=\leq 50 \%$ color change, $2=>50 \%$ color change, $3=$ missing. Estrus was defined to have occurred when an ED patch was scored 2 or 3. Cyclic heifers were inseminated with either frozen-thawed sex-selected or conventional semen from either of three sires available commercially (two per year). Acyclic heifers were inseminated with conventional semen. Pregnancy diagnosis was performed by transrectal ultrasonography 28 or $48 \mathrm{~d}$ after TAI, depending on management. The percentage of cyclic heifers was $83.9 \%$ and the average estrus response was $63.8 \%$. P/AI was greater $(P<0.01)$ in cyclic compared to acyclic heifers $(53.3 v s .36 .0 \%)$ and tended to be greater $(P=0.07)$ for conventional semen $(52.3 v$ s. $47.6 \%)$, despite all acyclic heifers being inseminated with conventional semen. Heifers with an ED patch scored $2(61.1 \%)$ or $3(58.6 \%)$ had greater $(\mathrm{P}<0.01) \mathrm{P} / \mathrm{AI}$ than those scored $0(31.8 \%)$ or 1 (33.1\%), regardless of semen type. Pregnancy per AI was greater $(P<0.01)$ for heifers detected in estrus $(60.6 v s .32 .3 \%)$. In cyclic heifers that did not exhibit estrus, $\mathrm{P} / \mathrm{AI}$ was lower $(\mathrm{P}<0.01)$ in those inseminated with sex-selected semen $(27.8$ vs. $45.9 \%)$, while in heifers that exhibited estrus, $\mathrm{P} / \mathrm{AI}$ only tended to be lower $(\mathrm{P}=0.08 ; 56.7$ vs. $65.5 \%)$. In summary, $\mathrm{P} / \mathrm{AI}$ was greater in cyclic heifers, in those inseminated with conventional semen and in those exhibiting estrus before TAI. The ED patches were considered useful to identify animals for TAI with sex-selected semen and could be used to increase the adoption of this technology in beef herds.
\end{abstract}

(c) 2018 Published by Elsevier Inc.

\footnotetext{
Part of the information in this manuscript was published previously as an abstract at the Annual Meeting of the International Embryo Technology Society, Austin, Texas, January 2017.

* Corresponding author. \#303, 7000 - 113 Street NW, Edmonton, AB, T6H 5T6, Canada.
}

E-mail address: marcos.colazo@gov.ab.ca (M.G. Colazo).

\section{Introduction}

The use of AI is low in the beef industry, with only about $7.6 \%$ of operations using AI [1]. The most common reasons given for not including AI on farm were labor/time, cost, level of difficulty, and lack of facilities [1]. However, as replacement heifers should be the 
genetically improved animals in the herd, the use of AI should facilitate the use of genetically improved bulls, and reduce trauma to heifers, variable breeding season lengths and calving dates [2]. In addition, the use of AI should provide more control over reproductive management, allowing for the use of sex-selected semen to increase the proportion of either replacement heifers or steers with greater feedlot potential.

In order to encourage implementation of $\mathrm{AI}$ in beef heifers, it is necessary to develop protocols that will yield high pregnancy per $\mathrm{AI}$ $(\mathrm{P} / \mathrm{AI})$ with a minimal increase in labor. Timed $\mathrm{AI}(\mathrm{TAI})$ protocols are beneficial, as they reduce the interval to first AI, reduce the need for estrus detection, and allow for synchronization of breeding groups [3]. The use of the modified 5-d Co-synch plus controlled internal drug release (CIDR) TAI protocol (without initial GnRH and only a single prostaglandin F2 $\alpha$; PGF) has resulted in P/AI that exceeded $60 \%$ in cycling dairy heifers $[4,5]$. However, administration of the initial GnRH in the 5-d Co-synch plus CIDR protocol was necessary in acyclic beef heifers to optimize P/AI [6].

Colazo and Ambrose [4] reported that more than $75 \%$ of cycling Holstein heifers ovulated within $24 \mathrm{~h}$ of TAI when the modified 5d Co-synch plus CIDR protocol was used, which has implications for the use of sex-selected semen. The use of sex-selected semen has been reported to result in P/AI that are $10 \%$ less than conventional semen [7], which contributes to its limited use in beef breeding programs. The reduced duration of optimal fertility of sexselected semen in the female reproductive tract means that sperm must be deposited in the uterus close to the time of ovulation [7]. Therefore, a protocol resulting in ovulation closer in time to TAI would be ideal.

Although a TAI protocol does not require estrus detection, an increase in P/AI in beef and dairy heifers has been reported when estrus was detected before insemination [8,9]. Macmillan et al. [5] also found a tendency for dairy heifers detected in estrus before TAI to have increased P/AI following insemination with sex-selected semen, which could be due to a shorter and less variable interval between $\mathrm{AI}$ and ovulation [8]. Estrus detection is labor and time consuming, therefore using estrus detection aids avoids the additional labor while having a high sensitivity and specificity for determining estrus [10]. In this regard, recent studies have reported that using Estrotect ${ }^{\mathrm{TM}}$ patches is beneficial for detecting estrus and determining time of insemination following the use of the $14 \mathrm{~d}$ CIDR-PGF protocol $[9,11]$ or the $7-d$ Co-synch plus CIDR protocol [11]; however, there are few if any reports on the use of Estrotect ${ }^{\mathrm{TM}}$ patches in the modified 5-d Co-synch plus CIDR protocol in beef heifers inseminated with either conventional or sex-selected semen. The main objective of this study was to determine if expression of estrus before TAI was associated with increased P/AI in cyclic beef heifers subjected to the modified 5-d Co-synch plus CIDR TAI protocol and inseminated with either conventional or sexselected semen. A secondary objective was also to determine if the expression of estrus before TAI would be associated with increased $\mathrm{P} / \mathrm{AI}$ in acyclic heifers inseminated with conventional semen. We hypothesized that heifers which show estrus before AI will have increased P/AI to the TAI protocol and that the difference in fertility between cyclic heifers that express estrus compared to those that do not would be greater when using sex-selected semen.

\section{Material and methods}

This study was carried out in three commercial beef herds (A, B and C) located near Edmonton, Alberta, Canada $\left(53.54^{\circ} \mathrm{N}\right.$, $113.49^{\circ} \mathrm{W}$ ), from April to May 2016 and in herds B and C from April to May 2017. All procedures were conducted in accordance with the guidelines of the Canadian Council on Animal Care [12].

\subsection{Animals and management}

The study subjects were Angus and Simmental crossbred beef heifers between 13 and $15 \mathrm{mo}$ of age and 320.0 and $522.7 \mathrm{~kg}$ of body weight (BW). All heifers were individually weighted once at the initiation of the study. Heifers were housed in dry lots and had unrestricted access to water and hay. In all three herds, heifers were fed once daily a diet composed mainly of barley silage, barley grain, plus a protein, vitamin and mineral supplement, which was designed for a daily gain of $0.7 \mathrm{~kg}$.

\subsection{Ovulation synchronization treatments for TAI and pregnancy diagnosis}

A total of 1690 heifers were examined by transrectal ultrasonography (MicroMAXX, color Doppler scanner equipped with a multifrequency 5-10 MHz linear transducer; SonoSite, Bothell, WS, USA) to determine cyclicity (presence of luteal tissue), pregnancy status and normalcy of the reproductive tract. Cyclic heifers were subjected to a modified 5-d Co-synch plus CIDR protocol (without initial GnRH and only a single PGF), whereas acyclic heifers received a 5-d Co-synch plus CIDR protocol, which includes the initial GnRH and a single PGF (Fig. 1). On Day 0,1331 cyclic heifers, at random stages of the estrous cycle, received a controlled internal drug release (CIDR; Zoetis Animal Health, Florham Park, NJ, USA) device containing $1.38 \mathrm{~g}$ of progesterone for $5 \mathrm{~d}$ with no further treatment. At CIDR removal (Day 5), $500 \mu \mathrm{g}$ im of cloprostenol (PGF; Estroplan or Bioestrovet; Vetoquinol N.-A Inc., Lavaltrie, QC, Canada) was administered and estrus detection (ED) patches (Estrotect $^{\mathrm{TM}}$; Rockway Inc., Spring Valley, WI, USA) were applied about mid-way between the hip and tail head. Hair was brushed in the
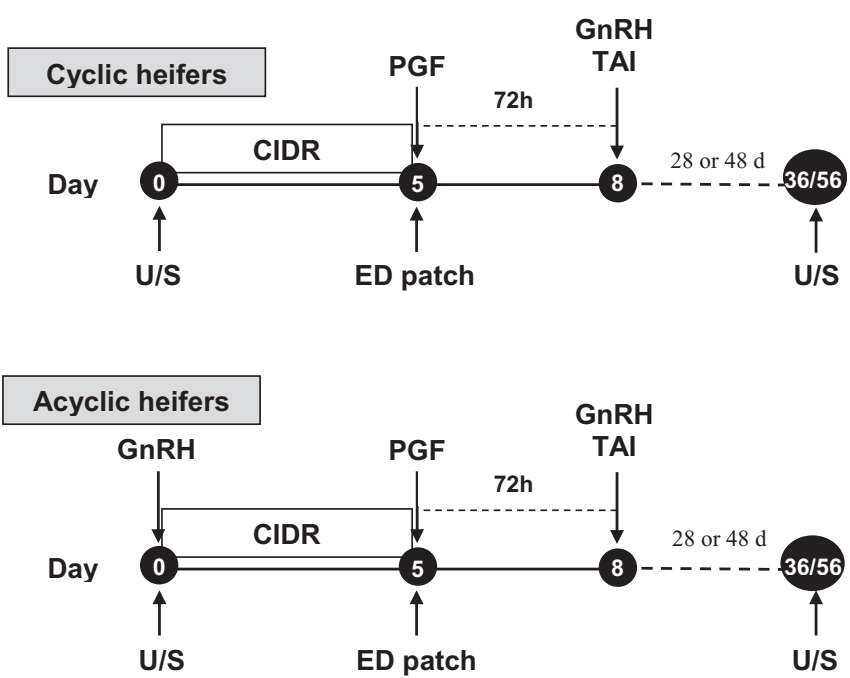

Fig. 1. Illustration of activities and treatments during the study. Crossbred cyclic heifers $(n=1331)$ received a progesterone releasing device containing $1.38 \mathrm{~g}$ of progesterone (CIDR) on Day 0, CIDR removal and $500 \mu \mathrm{g}$ of cloprostenol (PGF) on Day 5 , and $100 \mu \mathrm{g}$ of Fertiline (GnRH) along with timed-AI (TAI) on Day 8 (approximately $72 \mathrm{~h}$ after CIDR removal). Acyclic heifers $(n=275)$ received same treatments as cyclic heifers with the addition of GnRH on Day 0. On Day 5, all heifers received estrus detection (ED) patches (Estrotect) that were scored from 0 to 3, based on color change between initial application and Day 8; $0=$ unchanged, $1=\leq 50 \%$ color change, $2=>50 \%$ color change, $3=$ missing. Cyclic heifers were assigned by ear tag number to be inseminated with frozen-thawed sex-selected or conventional semen from either of two sires available commercially. Acyclic heifers were inseminated only with conventional semen. All heifers were inseminated by the same technician. Transrectal ultrasonography $(\mathrm{U} / \mathrm{S})$ was performed on Day 0 to determine cyclicity (presence of luteal tissue) and normalcy of the reproductive track, and 28 or $48 \mathrm{~d}$ after TAI to determine pregnancy status. 
area where the patch was to be placed (glue was only applied in 2017). On Day 8, ED patches were scored from 0 to 3, based on color change between initial application $(0=$ unchanged, $1=\leq 50 \%$ color change, $2=>50 \%$ color change, $3=$ missing) and heifers received $100 \mu \mathrm{g}$ im of GnRH (Fertiline; Vetoquinol N.-A Inc.) along with TAI (approximately $72 \mathrm{~h}$ after CIDR removal). Estrus was defined to have occurred when an ED patch was scored 2 or 3 at TAI. Estrus response (\%) was defined as the number of heifers with an ED patch scored 2 and 3 over the total number of heifers.

Acyclic heifers $(n=275)$ were treated similarly with the addition of $100 \mu \mathrm{g}$ im of GnRH (Fertiline; Vetoquinol N.-A Inc.) at the time of CIDR insertion.

Cyclic heifers were assigned using odd or even ear-tag numbers to be inseminated with frozen-thawed sex-selected or conventional semen from either of two sires available commercially (Alta Genetics Inc.). Bulls A and B were used in 2016, whereas, bulls B and $C$ were used in 2017; hence, semen from three bulls was used in the entire study. Acyclic heifers were inseminated only with conventional semen from same bulls used in cyclic heifers. The sperm concentration of sex-selected and conventional semen was $2.1 \times 10^{6}$ and $\sim 20 \times 10^{6}$ cells/dose, respectively. All heifers were inseminated by the same technician. A schematic representation of the synchronization protocols and activities during the study is shown in Fig. 1.

Pregnancy diagnosis was performed by transrectal ultrasonography (Easi-scan, scanner equipped with a multifrequency 4.5-8.5 MHz linear transducer, BCF Technology Ltd, Bellshill, Scotland, UK) 28 (year 2016, Herd A; year 2017 Herd C) or $48 \mathrm{~d}$ (year 2016 Herd C; years 2016 and 2017, Herd B) after TAI. Presence of a viable embryo/fetus (positive heart beat) was used as a determinant of pregnancy.

\subsection{Statistical analyses}

All data were analyzed using SAS (Statistical Analysis System, Version 9.4 for Windows; SAS Institute Inc., Cary, NC). Categorical data (cyclicity status, estrus response and $\mathrm{P} / \mathrm{AI}$ ) were analyzed by logistic regression models with the GLIMMIX procedure of SAS using the binomial distribution and link logit function. Herd (A, B and C) and year $(2016,2017)$ were included in the model to analyze cyclicity status at the initiation of synchronization, and in addition to herd and year, cyclicity status was included in the model when estrus response was analyzed. The following fixed independent variables were considered for inclusion in the model for $\mathrm{P} / \mathrm{AI}$ including all heifers: cyclicity (presence of luteal tissue at CIDR insertion), type of semen (conventional vs. sex-selected), ED patch scoring (4 categories), sire (3 categories), CIDR lost (yes vs. no), cyclicity by ED patch score interaction, type of semen by ED patch response interaction, and type of semen by sire interaction. Herd and year were initially tested as independent variables but both variables were included as random variables in the final model for $\mathrm{P} / \mathrm{AI}$. When analysis of P/AI was performed including only cyclic heifers, the following variables were tested: type of semen (conventional vs. sex-selected), ED patch score (4 categories), sire (3 categories), type of semen by ED patch score interaction, and type of semen by sire interaction. Backward stepwise logistic regression models were used, independent variables and their interactions were continuously removed from the models by the Wald statistic criterion when $\mathrm{P}>0.20$.

The effect of BW $(\mathrm{kg})$ on cyclicity at initiation of the synchronization program and estrus response was analyzed by ANOVA using the General Linear Model (GLM) procedure of SAS. Bartlett's test of equal variance was used to analyze variance, and the LSD test was used to compare means.

For all statistical analyses, a probability of 0.05 or less was considered statistically significant, and a probability between 0.051 and 0.1 was considered a tendency.

\section{Results}

\subsection{Culling, cyclicity (presence of luteal tissue) and body weight prior to initiation of synchronization}

A total of 84 heifers were culled at the initiation of the study ( 8 had pyometra, 19 had BW $<320.0 \mathrm{~kg}, 22$ were Freemartin, and 35 were pregnant). Overall, $17.1 \%$ (275/1606) of heifers were determined acyclic by transrectal ultrasonography at the initiation of the synchronization. The percentage of cyclic heifers ranged from 72.3 to $90.7 \%$ and cyclicity was associated to herd and year (Table 1 ).

Body weight (mean \pm SD) was $407.2 \pm 38.0 \mathrm{~kg}$ (range $320.0-522.7 \mathrm{~kg})$. Cyclic heifers were on average heavier $(\mathrm{P}<0.01)$ than acyclic heifers $(409.9 \pm 38.3$ vs. $391.8 \pm 32.4 \mathrm{~kg})$. Heifers were on average heavier in 2016 compared to $2017(\mathrm{P}<0.01 ; 413.2 \pm 37.8$ vs. $396.3 \pm 36.0 \mathrm{~kg})$. However, heifer's BW did not differ among herds $(P=0.2)$.

\subsection{Estrus response}

The overall estrus response based on ED patch score was $63.8 \%$ (1024/1606). Herd, year, cyclicity status and BW were all factors associated with estrus response. Herd $C$ had lower $(P<0.01)$ estrus response (60.7\%) compared to Herds $A(65.7 \%)$ and $B(66.8 \%)$. Estrus response in 2016 was greater than that in $2017(\mathrm{P}<0.01 ; 68.1$ vs. $57.0 \%)$. Cyclic heifers were more likely to be in estrus before TAI compared to acyclic heifers ( $\mathrm{P}<0.01 ; 67.9$ vs. $43.6 \%$ ) and heifers that exhibited estrus were heavier than those that did not exhibit estrus $(\mathrm{P}<0.01 ; 410.0 \pm 38.5$ vs. $402.6 \pm 36.8 \mathrm{~kg})$.

\subsection{Pregnancy per $A I$}

Overall P/AI was 50.4\% (809/1606) and it was affected significantly by herd and year (Table 2 ). The CIDR retention rate was $97.4 \%$ (1564/1606) and heifers that lost the CIDR had lower P/AI compared to those that did not lose the CIDR ( $\mathrm{P}<0.01 ; 23.8$ vs. $51.1 \%)$.

The P/AI based on ED patch scoring, cyclicity status and type of semen is shown in Table 3. Overall, $\mathrm{P} / \mathrm{AI}$ was greater $(\mathrm{P}<0.01)$ in heifers with an ED patch scored $2(502 / 821,61.1 \%)$ or $3(119 / 203$, $58.6 \%)$ than those with an ED patch scored $0(109 / 343,31.8 \%)$ or 1 (79/289, 33.1\%). However, when only cyclic heifers were included in the analysis, the effect of estrus response on P/AI depended on type of semen (Fig. 2). In heifers that did not exhibit estrus, P/AI was significantly lower $(\mathrm{P}<0.01)$ for sex-selected semen compared to conventional semen [27.8\% (58/209) vs. 45.9\% (100/218)], while P/

Table 1

Number and percentage of cyclic ${ }^{\mathrm{a}}$ heifers by farm and year.

\begin{tabular}{llll}
\hline Farm & Year & Overall \\
\cline { 2 - 3 } & 2016 & 2017 & \\
\hline A & $272 / 300(90.7)$ & - & $272 / 300(90.7)^{\mathrm{a}, \mathrm{y}}$ \\
$\mathrm{B}$ & $251 / 302(83.1)$ & $183 / 253(72.3)$ & $434 / 555(78.2)^{\mathrm{b}, \mathrm{y}}$ \\
C & $317 / 378(83.9)$ & $308 / 373(82.6)$ & $625 / 751(83.2)^{\mathrm{a}, \mathrm{x}}$ \\
Overall & $840 / 980(85.7)^{\mathrm{c}}$ & $491 / 626(78.4)^{\mathrm{d}}$ & $1331 / 1606(82.9)$ \\
\hline
\end{tabular}

$\mathrm{a}, \mathrm{b}$ Within a columm and category, percentages without a common superscript differ $(\mathrm{P}<0.01)$.

${ }^{\mathrm{x}, \mathrm{y}}$ Within a columm and category, percentages without a common superscript tend to differ $(\mathrm{P}=0.08)$.

c,d Within a row and category, percentages without a common superscript differ $(\mathrm{P}<0.05)$.

a Cyclicity status (presence of luteal tissue) was determined by transrectal ultrasonography at the initiation of synchronization. 
Table 2

Number of heifers and pregnancy per $\mathrm{AI}(\mathrm{P} / \mathrm{AI} ; \%)$ by farm and year.

\begin{tabular}{llll}
\hline \multirow{2}{*}{ Farm } & Year & \multicolumn{1}{l}{ Overall } \\
\cline { 2 - 3 } & 2016 & 2017 & \\
\hline A & $178 / 300(59.3)$ & - & $178 / 300(59.3)^{\mathrm{a}}$ \\
$\mathrm{B}$ & $151 / 302(50.0)$ & $95 / 253(37.5)$ & $246 / 555(44.3)^{\mathrm{b}}$ \\
$\mathrm{C}$ & $212 / 378(56.1)$ & $173 / 373(46.4)$ & $385 / 751(51.3)^{\mathrm{a}}$ \\
Overall & $541 / 980(55.2)^{\mathrm{a}}$ & $268 / 626(42.8)^{\mathrm{b}}$ & $809 / 1606(50.4 \%)$ \\
\hline
\end{tabular}

a,b Within a columm or a row, percentage without a common superscript differ $(\mathrm{P}<0.01)$.

AI tended to be lower $(\mathrm{P}=0.08)$ in heifers that exhibited estrus and were inseminated with sex-selected semen [56.7\% (258/455) vs. 65.5\% (294/449)].

Cyclicity status and type of semen were also associated with $\mathrm{P} /$ AI. Despite all acyclic heifers being inseminated with conventional semen, cyclic heifers had greater $\mathrm{P} / \mathrm{AI}$ than acyclic heifers $(\mathrm{P}<0.01$; 53.3 vs. $36.0 \%$ ) and conventional semen tended to yield greater $\mathrm{P} / \mathrm{AI}$ than sex-selected semen ( $\mathrm{P}=0.07 ; 52.3$ vs. $47.6 \%)$. When acyclic heifers were excluded from the analysis, P/AI was greater for conventional semen than for sex-selected semen $(P<0.01 ; 59.1$ vs. $47.6 \%)$.

Sire tended to affect $(\mathrm{P}=0.07) \mathrm{P} / \mathrm{AI}$, but the interaction between sire and type of semen did not affect $\mathrm{P} / \mathrm{AI}(\mathrm{P}=0.4$; Table 4$)$.

\section{Discussion}

Implementation of an AI program in beef heifers, especially one using sex-selected semen, must yield acceptable P/AI but also minimize labor. The use of a TAI protocol allows for tight synchronization of ovulation in breeding groups and the modified 5d Co-synch plus CIDR protocol (without initial GnRH and a single PGF) requires only three handlings and reduced hormone use. The objective of this study was to determine if including estrus detection in the modified 5-d Co-synch plus CIDR TAI protocol would impact fertility in beef heifers, particularly when using sex-selected semen. Our results show that the modified 5-d Co-synch plus CIDR protocol was effective in cyclic heifers and led to acceptable P/AI when using sex-selected semen. Additionally, the occurrence of estrus before TAI resulted in increased P/AI, which was especially important when sex-selected semen was used.

The overall $\mathrm{P} / \mathrm{AI}$ was $50 \%$, which includes $17 \%$ acyclic heifers and the use of sex-selected semen in 50\% of cyclic heifers. When considering only the cyclic heifers inseminated with conventional semen the P/AI with the modified 5-d Co-synch was 59\%, which is similar to the $62 \%$ reported by López-Helguera et al. [6] who used the same protocol in beef heifers. Previous studies have shown that $\mathrm{P} / \mathrm{AI}$ following the use of the modified 5-d Co-synch protocol were

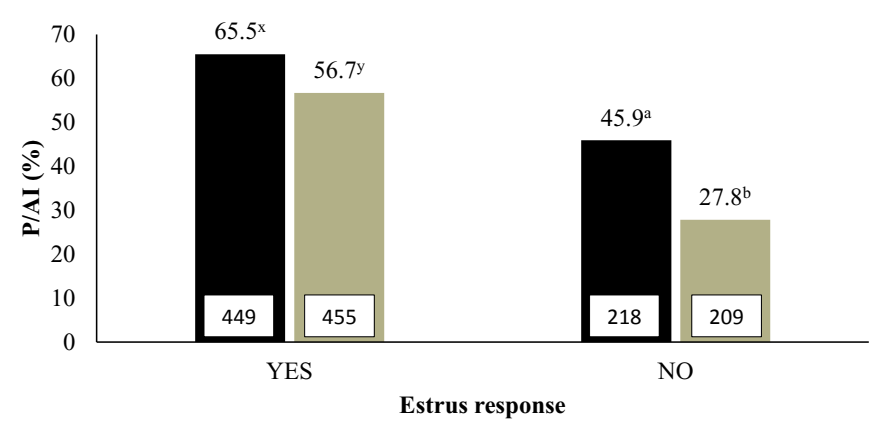

- Conventional semen $\quad$ Sex-selected semen

Fig. 2. Pregnancy per $\mathrm{AI}(\mathrm{P} / \mathrm{AI} ; \%)$ in cyclic heifers $(\mathrm{n}=1331)$ based on estrus response and type of semen. Heifers received a progesterone releasing device containing $1.38 \mathrm{~g}$ of progesterone (CIDR) on Day 0, CIDR removal and $500 \mu \mathrm{g}$ of cloprostenol (PGF) on Day 5, and $100 \mu \mathrm{g}$ of Fertiline (GnRH) along with timed-AI (TAI) on Day 8 (approximately $72 \mathrm{~h}$ after CIDR removal). On Day 5 , all heifers received estrus detection (ED) patches that were scored from 0 to 3 , based on color change between initial application and Day $8 ; 0=$ unchanged, $1=\leq 50 \%$ color change, $2=>50 \%$ color change, $3=$ missing. Estrus was defined to have occurred when an ED patch was scored 2 or 3 at TAI. Heifers were assigned by ear tag number to be inseminated by the same technician with frozen-thawed sex-selected or conventional semen. Transrectal ultrasonography was performed 28 or $48 \mathrm{~d}$ after TAI to determine pregnancy status. In heifers that did not exhibit estrus, PAI was significantly lower $(\mathrm{P}<0.01)$ in those inseminated with sex-selected semen, while in heifers that exhibited estrus, P/AI tended to be lower in those inseminated with sex-selected semen. ${ }^{\mathrm{a}, \mathrm{b}}$ Within a category, percentages without a common superscript $\operatorname{differ}(\mathrm{P}<0.01){ }^{\mathrm{x}, \mathrm{y}}$ Within a category, percentages without a common superscript tend to differ $(P=0.08)$.

similar to the use of estrus detection only [8], and that removing the initial GnRH and using one PGF treatment does not compromise fertility in cyclic heifers [5,6,13]. Conversely, Kasimanickam et al. [14] did find that including the initial GnRH increased P/AI by $10 \%$ in beef heifers, but had no effect in dairy heifers; however, cyclicity was not reported and as beef heifers are more likely to be acyclic, the initial GnRH may have been more beneficial in beef heifers. In this regard, López-Helguera et al. [6] observed an increase in P/AI when the initial GnRH was given to acyclic heifers (48 vs. $35 \%$, $P<0.01$ ), which contributed to our decision to treat all the acyclic heifers in the current study with GnRH at the time of CIDR insertion. Even with the use of the initial GnRH in the current study, P/AI in acyclic heifers was only $36 \%$, and the estrus response was low (44\%). Despite the ovulatory response to the first GnRH in the 5d Co-synch protocol being low in heifers [4], if GnRH does induce ovulation in acyclic heifers a second PGF treatment may be beneficial in inducing luteolysis prior to $\mathrm{AI}$ and increasing the estrus response, as well as increasing P/AI [15]. Overall, the modified 5d Co-synch protocol appears to be an effective protocol for TAI in cyclic heifers, but in acyclic heifers, an initial GnRH and two injections of PGF would appear to be more beneficial.

Table 3

Pregnancy per $\mathrm{AI}[\%(n)]$ based on cycling status at the initiation of synchronization ${ }^{\mathrm{a}}$, type of semen, and estrus detection (ED) patch scoring.

\begin{tabular}{|c|c|c|c|c|c|c|}
\hline \multirow[t]{2}{*}{ Cycling status $^{\mathrm{b}}$} & \multirow[t]{2}{*}{ Type of semen } & \multicolumn{4}{|l|}{ ED patch scoring ${ }^{c}$} & \multirow[t]{2}{*}{ Overall $[\%(n / n)]$} \\
\hline & & 0 & 1 & 2 & 3 & \\
\hline Acyclic & Conventional & $18.4(18 / 98)$ & $21.1(12 / 57)$ & $56.7(56 / 99)$ & $61.9(13 / 21)$ & $36.0(99 / 275)$ \\
\hline Cyclic & Conventional & $44.2(57 / 129)$ & $48.3(43 / 89)$ & $66.9(239 / 357)$ & $59.8(55 / 92)$ & $59.1(394 / 667)$ \\
\hline Cyclic & Sex-selected & $29.3(34 / 116)$ & $25.8(24 / 93)$ & $56.7(207 / 365)$ & $56.6(51 / 90)$ & $47.6(316 / 664)$ \\
\hline Overall [\% (n)] & & $31.8^{\mathrm{a}}(109 / 343)$ & $33.1^{\mathrm{a}}(79 / 239)$ & $61.1^{\mathrm{b}}(502 / 821)$ & $58.6^{\mathrm{b}}(119 / 203)$ & $50.4(809 / 1606)$ \\
\hline
\end{tabular}

a,b Within a row and category, percentage without a common superscript differ $(\mathrm{P}<0.01)$.

a Crossbred cyclic heifers $(\mathrm{n}=1331)$ received a progesterone releasing device containing $1.38 \mathrm{~g}$ of progesterone (CIDR) on Day 0 , CIDR removal and $500 \mu \mathrm{g}$ of cloprostenol

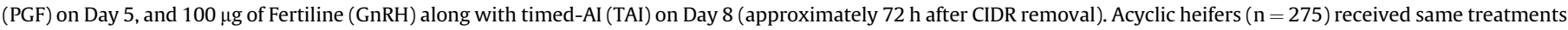
as cyclic heifers with the addition of GnRH on Day 0.

b Cyclicity status (presence of luteal tissue) was determined by transrectal ultrasonography at the initiation of synchronization.

c At CIDR removal (Day 5), heifers received ED patches (Estrotect) that were scored from 0 to 3, based on color change between initial application and TAI (Day 8); $0=$ unchanged, $1=\leq 50 \%$ color change, $2=>50 \%$ color change, $3=$ missing. 
Table 4

Number of heifers and pregnancy per $\mathrm{AI}(\mathrm{P} / \mathrm{AI}$; \%) based on sire and type of semen.

\begin{tabular}{llll}
\hline Sire & Type of semen & & Overall \\
\cline { 2 - 3 } & Conventional & Sex-selected & \\
\hline A & $156 / 275(56.7)$ & $118 / 215(54.9)$ & $271 / 490(55.9)^{\mathrm{a}}$ \\
B & $248 / 475(52.2)$ & $146 / 329(44.4)$ & $394 / 804(49.0)^{\mathrm{a}, \mathrm{b}}$ \\
$\mathrm{C}$ & $89 / 190(46.8)$ & $52 / 122(42.6)$ & $141 / 312(45.2)^{\mathrm{b}}$ \\
\hline
\end{tabular}

a,b Within a column, percentages without a common superscript $\operatorname{differ}(\mathrm{P}<0.05)$.

Although TAI does not necessitate ED, other studies have shown that P/AI increased when heifers were in estrus before TAI $[5,9,16]$. The use of Estrotect ${ }^{\mathrm{TM}}$ patches allows for ED with a minimum increase in labor and they have been shown to be very efficacious in determining estrus in heifers [10] based on when $50 \%$ or more of the patch had changed color. In the current study, $12 \%$ of heifers were missing patches (score 3 ) and as the P/AI was 59\% in this group this was seen as a positive sign for estrus. This did not differ from the $61 \% \mathrm{P} / \mathrm{AI}$ in heifers with patches with $\geq 50 \%$ color change (score 2). The estrus response in the current study was 64\%, which is similar to the results of previous studies using the Estrotec patches for ED in beef heifers [9,11]. In addition, heifers considered in estrus before TAI had a greater P/AI compared to those not in estrus (61 vs. 32\%). Richardson et al. [17], found a similar $27 \%$ increase in $\mathrm{P} / \mathrm{AI}$ in females that showed estrus before TAI following a meta-analysis with 10,000 beef females across 22 studies. We have previously reported that ovulations within $24 \mathrm{~h}$ after AI result in higher P/AI in Holstein heifers subjected to a similar TAI protocol [4] and that the interval from AI to ovulation was shorter and less variable when heifers were inseminated on ED compared with TAI $(16 \pm 0.7$ vs. $21.2 \pm 1.3 \mathrm{~h} ; P<0.05$; [8]). This also has implications for the use of sex-selected semen as the decrease in fertility is likely associated with the reduced duration of optimal fertility in the female reproductive tract [7]. Therefore, it is essential that ovulation occurs soon after insemination with sex-selected semen. In addition to improved timing between semen deposition and ovulation, the expression of estrus is initiated by increased concentrations of estradiol [18], which will influence pregnancy rates. Increased estradiol concentrations have been reported to alter the uterine environment in preparation for mating, which includes changing the composition and amount of cervical mucous enhancing uterine contractions for sperm transport [19], altering uterine $\mathrm{pH}$ increasing lifespan of sperm [18], and increasing oviduct secretions improving fertilization rates [20,21]. Although ovulation is induced by a TAI protocol, the expression of estrus before AI and ovulation indicates an optimal timing of sperm deposition in the female reproductive tract.

Although the overall P/AI was lower when sex-selected semen was used compared to conventional semen ( 48 vs. 59\%), results are similar to those reported previously using a variety of ovulation synchronization protocols [9,16,22]. However, when estrus was detected prior to AI, P/AI only tended to be lower when sexselected semen was used (57 vs. 66\%). In dairy heifers, Macmillan et al. [5] reported a $10 \%$ increase in P/AI with sex-selected semen when the modified 5-d Co-synch plus CIDR was used compared to a standard 5-d Co-synch that included an initial GnRH. The authors attributed this increase to a greater percentage of heifers in modified 5-d Co-synch group being in estrus $24 \mathrm{~h}$ before TAI ( $22 \mathrm{vs.}$ $14 \%, P=0.03$ ). Hall et al. [23] used the traditional 5-d Co-synch plus CIDR protocol (with initial GnRH and two treatments of PGF) in beef cows and determined whether delaying insemination with sexselected semen by $8 \mathrm{~h}$ ( 80 vs. $72 \mathrm{~h}$ after CIDR removal) would result in higher P/AI. However, despite an increase in the number of heifers detected in estrus before AI, there was no increase in P/AI, which may indicate that the timing of $\mathrm{AI}$ relative to estrus is more important than simply delaying TAI. This study makes the point that the detection of estrus in a TAI protocol may be essential for optimal fertility, especially when sex-selected semen is used.

One way that estrus detection before TAI can be used for reproductive management of beef heifers is to decide which animals receive sex-selected or conventional semen. As sex-selected semen has increased cost and reduced fertility, it should only be used in heifers showing estrus before TAI in order to maximize P/AI. For heifers not detected in estrus, conventional semen can be used for TAI without seriously compromising P/AI. In the current study, $\mathrm{P} / \mathrm{AI}$ of $46 \%$ was achieved conventional semen compared to $28 \%$ following the use of sex-selected semen in heifers that did not show estrus. However, to maximize fertility, regardless of type of semen used, another option might be to use split-time AI (STAI), which involves delaying $\mathrm{AI}$ by $24 \mathrm{~h}$ in animals that were not determined to be in estrus at the selected time of TAI [9,11]. Thomas et al. [9] submitted beef heifers to a $14 \mathrm{~d}$ CIDR-PGF protocol with STAI and no GnRH given at AI and achieved a P/AI of 52\% using sexselected semen. In this study, Estrotect ${ }^{\mathrm{TM}}$ patches were also used for ED and $64 \%$ of the heifers showed estrus prior to the first AI, but when those inseminated $24 \mathrm{~h}$ later were included, the cumulative estrus rate was $89 \%$. Similarly, Bishop et al. [11] used the same protocol and Estrotect ${ }^{\mathrm{TM}}$ patches for STAI in beef heifers with conventional semen and reported estrus rates of approximately 70 , 54 and $86 \%$ for initial AI, delayed $\mathrm{AI}$ and overall estrus response. The authors also compared giving GnRH before AI, concurrently with AI, or giving no GnRH and found that removing GnRH had no effect on pregnancy risk in heifers determined to be in estrus at the time of either insemination. Using ED and STAI significantly increased the proportion of heifers that showed estrus before AI, which improved the overall fertility with both conventional and sex-selected semen. Additionally, heifers showing estrus may not require the administration of GnRH at TAI, which would further decrease cost and hormone usage.

Determining cyclicity before the initiation of the breeding protocol was also included in the current study as part of a practical program for beef heifers. As the pregnancy risk for acyclic heifers is greatly reduced compared to cyclic heifers, identifying acyclic animals allows for intervention to improve fertility. In the current study, transrectal ultrasonography was used to determine cyclicity, which increases veterinary costs for a producer, but also allows for the diagnosis of heifers unfit for breeding. Another option previously tested is to use the Estrotect ${ }^{\mathrm{TM}}$ patches to determine cyclicity before breeding, which allowed for the identification of $79 \%$ of cyclic and $86 \%$ of acyclic beef heifers before initiation of a breeding protocol in one study [10]. Body weight also played a significant role for cyclicity as cyclic heifers were, on average, $18 \mathrm{~kg}$ heavier than acyclic heifers, similat to recent results from López-Helguera et al. [6]. Additionally, there appeared to be a significant effect of year on cyclicity and fertility in the current study. From 2016 to 2017, there was a $17 \mathrm{~kg}$ decrease in BW, an $8.5 \%$ decrease in proportion of heifers cycling at the time of initiating breeding, a $16 \%$ decrease in estrus response, and a $23 \%$ decrease in P/AI. The difference from 2016 to 2017 could be due to nutrition or management factors that were not measured in this study or perhaps because farm A was not represented in 2017. However, we did observe a difference in weather conditions between years. The average temperature and humidity for the area of study during the month of April were $9{ }^{\circ} \mathrm{C}$ and $52 \%$ in 2016 and $3{ }^{\circ} \mathrm{C}$ and $76 \%$ in 2017 [24]. Colder and more humid conditions during the study in 2017 could have increased stress levels in the animals, as well as resulted in a greater loss of ED patches compared to 2016 (21 vs. 7\% missing) despite using glue in 2017. Although fertility seemed to decline in 2017, results still indicate that the occurrence of estrus before AI improved P/AI, especially when using sex-selected semen. 


\section{Conclusions}

The use of a modified 5-d Co-synch plus CIDR protocol resulted in an overall $53 \% \mathrm{P} / \mathrm{AI}$ in cyclic heifers using either conventional and sex-selected semen. The 5-d Co-synch plus CIDR protocol with the initial GnRH in acyclic heifers still resulted in low P/AI. The use of the Estrotect ${ }^{\mathrm{TM}}$ patches was shown to be useful in detecting estrus, and heifers in estrus before TAI had greater P/AI regardless of cyclicity status or semen type. There was reduced fertility when sex-selected semen was used compared to conventional semen, but when estrus was detected before AI, P/AI only tended to be lower with the use of sex-selected semen. In summary, the occurrence of estrus before TAI increased fertility in beef heifers, with a greater increase observed when sex-selected semen was used. The use of estrus detection patches in a TAI protocol would appear to be an efficacious approach to improving reproductive efficiency and determining which heifers could be inseminated with sex-selected semen.

\section{Acknowledgments}

Research was supported by Livestock Research Section, Alberta Agriculture and Forestry. Authors thank Vetoquinol N.-A Inc. (Lavaltrie, QC, Canada), Alta Genetics Inc. (Balzac, Alberta) and Rockway Inc. (Spring Valley, WI, USA) for their in-kind support and the Horn family (Devon, Alberta, Canada) and the Crow families (Thorsby, Alberta, Canada) for their cooperation during the study.

\section{References}

[1] National Animal Health Monitoring System (NAHMS). Beef - Part II: reference of beef cow-calf management practices in the United States. Fort Collins, CO: USDA-APHIS Center for Epidemiology and Animal Health; 2008.

[2] Ribeiro ES, Galvao KN, Thatcher WW, Santos JEP. Economic aspects of applying reproductive technologies to dairy herds. Anim Reprod 2012;9:370-87.

[3] Colazo MG, Mapletoft RJ. A review of current timed-AI (TAI) programs for beef and dairy cattle. Can Vet J 2014;55:772-80.

[4] Colazo MG, Ambrose DJ. Neither duration of progesterone insert or initia GnRh treatment affected pregnancy per timed-insemination in dairy heifers subjected to a Co-sync protocol. Theriogenology 2011;76:578-88.

[5] Macmillan K, Loree K, Mapletoft RJ, Colazo MG. Short communication: optimization of a timed artificial insemination program for reproductive management of heifers in Canadian dairy herds. J Dairy Sci 2017;100:4134-8.

[6] López-Helguera I, Whittaker P, Behrouzi A, Mapletoft RJ, Colazo MG. Effect of initial GnRH and time of insemination in reproductive performance in cyclic and acyclic beef heifers subjected to a 5-d Co-synch plus progesterone protocol. Theriogenology 2018;106:39-45.

[7] Seidel Jr GE. Update on sexed semen technology in cattle. Animal 2014;8: $160-4$.

[8] Colazo MG, Mapletoft RJ. Pregnancy per AI in Holstein heifers inseminated with sex-selected or conventional semen after estrus detection or timed-AI. Can Vet J 2017;58:365-70.

[9] Thomas JM, Locke JWC, Vishwanath R, Hall JB, Ellersieck MR, Smith MF, et al. Effective use of SexedULTRATM sex-sorted semen for timed artificial insemination of beef heifers. Theriogenology 2017:98:88-93.

[10] Davis AJ, Rorie RW, Powell JG, Lester TD, Lindsey BR. Serial use of EstrotectTM estrous detection patches as a reproductive management tool. 2014. Pages 18-20 in Arkansas Animal Science Department Report.

[11] Bishop BEJ, Thomas M, Abel JM, Poock SE, Ellersieck MR, Smith MF, et al. Splittime artificial insemination in beef cattle: I-using estrous response to determine the optimal time(s) at which to administer GnRH in beef heifers and postpartum cows. Theriogenology 2016;86:1102-10.

[12] Canadian Council on Animal Care (CCAC). In: Guide to the Care and use of experimental animals. second ed., vol. 1. Ottawa, Ontario, Canada: CCAC; 2009.

[13] Cruppe LH, Day ML, Abreu FM, Kruse S, Lake SL, Biehl MV, et al. The requirement of $\mathrm{GnRH}$ at the beginning of the five-day Co-synch + controlled internal drug release protocol in beef heifers. J Anim Sci 2014;92:4198-203.

[14] Kasimanickam RK, Firth P. Schuenemann GM, Whitlock BK, Gay JM, Moore DA et al. Effect of the first GnRH and two doses of PGF2a in a 5-day progesteronebased Co-Synch protocol on heifer pregnancy. Theriogenology 2014;81: 797-804.

[15] Lima FS, Ribeiro ES, Bisinotto RS, Greco LF, Martinez N, Amstalden M, et al. Hormonal manipulations in the 5-day timed artificial insemination protocol to optimize estrous cycle synchrony and fertility in dairy heifers. J Dairy Sci 2013:96:7054-65.

[16] Mallory DA, Lock SL, Woods DC, Poock SE, Patterson DJ. Hot topic: comparison of sex-sorted and conventional semen within a fixed-time artificial insemination protocol designed for dairy heifers. J Dairy Sci 2013;96:854-6.

[17] Richardson BN, Hill SL, Stevenson JS, Djira GD, Perry GA. Expression of estrus before fixed-time $\mathrm{AI}$ affects rates and factors that impact expression of estrus and the repeatability of expression of estrus in sequential breeding seasons. Anim Reprod Sci 2016:166:133-40.

[18] Perry GA, Perry BL. Effect of preovulatory concentrations of estradiol and initiation of standing estrus on uterine $\mathrm{pH}$ in beef cows. Domest Anim Endocrinol 2008;34:333-8.

[19] Hawk HW. Sperm survival and transport in the female reproductive tract. J Dairy Sci 1983;66:2645-60.

[20] Buhi WC. Characterization and biological roles of oviduct-specific, oestrogendependent glycoprotein. Reproduction 2002;123:355-62.

[21] Rodriguez-Martinez H. Role of the oviduct in sperm capacitation. Theriogenology 2007;68(Suppl):138.

[22] Silva TV, Lima FS, Thatcher WW, Santos JEP. Synchronized ovulation for first insemination improves reproductive performance and reduces cost per pregnancy in dairy heifers. J Dairy Sci 2015;98:7810-22.

[23] Hall JB, Kasimanickam RK, Glaze Jr JB, Roberts-Lew MC. Impact of delayed insemination on pregnancy rates to gender selected semen in a fixed-time AI system. Theriogenology 2017:102:154-61.

[24] Time and Date. Past weather in Edmonton. Alberta, Canada, https://www. timeanddate.com. [Accessed 7 December 2017]. 